IBIMA Publishing

Journal of African Research in Business \& Technology

http://ibimapublishing.com/articles/JARBT/2017/523298/

Vol. 2017 (2017), Article ID 523298, 7 pages

DOI: $10.5171 / 2017.523298$

Research Article

\title{
Neutrality of New Technologies of Information and Communication in Organizations
}

\author{
Azzaz Fatima Ezzahra and Salahddine Abdelouhab
}

University Abdelmalek Saadi, ENCG Tangier Morocco

Correspondence should be addressed to: Fatima Ezzahra Azzaz; azzazfa@gmail.com

Received date: 25 November 2016; Accepted date: 25 April 2017; Published date: 5 June 2017

Academic Editor: Mohamed Abed

Copyright (C) 2017. Azzaz Fatima Ezzahra and Salahddine Abdelouhab. Distributed under Creative Commons CC-BY 4.0

\begin{abstract}
The profusion of "new information and communication technologies" within organizations marked the current context. These "technical objects" complex subject of numerous disciplines and approaches faces the theoretical controversy over the links between ICTs and the effects of their organizational purposes. A dividing line between «those making technical neutral tools, and technical progress not a questionable thesis ", and" those who detect an instrument of power and domination, a space combine to constantly balance of power it takes to unveil ". It is in this context that we are interested in the "non-neutrality" of these flexible technologies by their nature in terms of interpretation. On this basis, any new technology would carry, in itself, social implications, psychological, environmental, economic and political. That means if it is no technological determinism, there is no more than pure technological neutrality, and if the technique is not neutral, so it is oriented. (Orlikowski, 1992; Tyre \& Orlikowski, 1994). The debate on the possible "neutral" technology "tool" or "mood" within organizations reflects its ambiguity: it can deliver the best as it can give the worst. Therefore, we are interested not in static artifacts evolution "technology" but we want to know how they fit into an organization, to identify how they are updated in a changing environment.
\end{abstract}

Keywords: Technological neutrality, ICT, impact, organization

\section{Introduction}

We are currently experiencing a phase of extremely rapid changes in almost all fields of human existence. These changes are mainly caused by the developments of new information and communication technologies which have largely altered the way we see things and even the way we experience time and space.

Our goal is to enter the weight and importance of technology in organizational

Cite this Article as: Azzaz Fatima Ezzahra and Salahddine Abdelouhab (2017), "Neutrality of New Technologies of Information and Communication in Organizations ", Journal of African Research in Business \& Technology, Vol. 2017 (2017), Article ID 523298, DOI: 10.5171/2017. 523298 
operations and to examine the neutrality of this technology within the organization: is a neutral activity? In other words, it is a simple way that enjoys a neutrality principle or is only apparent and that in practice we have a situation of reciprocal influence between technology-actororganization, that technology can marginalize actors, incite division and block the flow of knowledge within the organization?

We therefore assume two premises:

- The technologies are neutral and there is no reason to pretend that they have influence on the organization and implicitly on the actor "user"

- Technologies go beyond the status of a simple tool to "a state of mind" that carries in itself a fantasy and creates new arrangements within the organization.

First, we ask the question what is a neutral activity: someone or something neutral is not marked by any connotation, no feeling, objective and impartial. Neutral therefore designates certain inertia and a lack of consequences. Neutrality is in another sense not to take sides in the choice of values and in determining purposes. In fact, take neutral position is a statement that is isolated and abroad at any party and we undertake no obligation in one way or another.

To claim a neutral state is therefore to indicate the innocence of the tool. The question we ask ourselves is whether technology can deny such status within the organization.

\section{Technology: a neutral tool within the organization}

Generally, we see in technology - which was developed with a very high penetration rate - only one aspect. We are blind: the functionality seen, instrumentality (what and who it is) but not the essence, the genesis and the imaginary dimension that probably influences the organization and the actor.

In other words, can technology remain to be only a set of resources? The choice of efficiency and organizational performance as a reason to implement and use technology is not, in fact, already a bias that brought us out of technological neutrality? This question marked the debate in several multidisciplinary areas mainly philosophy, anthropology, sociology of work....

The standard approach to technology (Smith, 1776; Ricardo, 1995; and Babbag, 1971) is to consider it as neutral that technology is only a set of applications and scientific knowledge does not carry in itself of valuesand implications. Moreover, as it is based on "scientific" truths objectively verified, technology is morally neutral.

The neutrality of technology is supported by a dual argument: All humans use the technology and the sciences we use to improve them are morally neutral. (Zerzan, 2002) . Both statements can be refuted, and by doing so we progress towards critical thinking technology.

Indeed, the literature is not abundant at this level; it is generally seen that it is by implication that we tend to separate the issue of the use of technological issue under the pretext that it is neutral and we cannot - by definition - apply values to it since only the actor can give meaning to his actions.

On this basis, the article "The military and the use of technology" indicated that technology is morally neutral, that is the way it is used is in question. This Current qualified sense of instrumentalism treated technology as a neutral medium, requiring no special explanation or justification. Thus, technology was again thought simply as an aspect of organizational routine. Neutral technique was assumed since it does not alter the natural ends and only shortens the path to their satisfaction. This neutralization of technology removed him even more from political controversy from a philosophical point of view (Foucault 1975; Bentham 1791; Saint-Simon 1819).

Common sense or instrumentalist current (Vernant, 1965; Miquel and Menard, 1988) admits the possibility of human control and neutrality of technology. Determinism presented by traditional Marxism, 
minimizes our ability to control technical development, but considers that the technical means are neutral to the extent that they simply meet the natural needs (Feenberg, 2004, p. 32).

Determinism claims that techniques obey an autonomous functional logic that can be explained without reference to society. The technique thus resembles science and mathematics by its intrinsic independence vis-à-vis the social world. (Marx 1847, p. $100)$. It is based on the belief, more or less explicit, that a properly developed technique can only be imposed on players and organization (B. Rorive, 2003).

The deterministic thinking is interested in the relationship established between technology and the environment. This is a principle which says that the technology does not evolve in society but that society evolves with technology. (Vinck 1995) Technological determinism can be summarized by the following example: the Internet which has created social change and not the development and change of the companies that led to the advent of Internet (Vendramin 2005)

Somehow, the essentialist theories of technique approach certain determinism insofar as technology is always perceived as an ineluctable and autonomous consequence of a progress itself considered as "unilinéaire and automatic". The technology is perceived as determining the path of development to follow, as a search for efficiency. However, one major difference between determinism and essentialism is that determinism considers art as neutral in itself (as in traditional Marxism) as an extension of human action as essentialism says that the technique is not neutral and embodies specific values, oriented domination (as Heidegger and Ellul example).

"If we neutralize the discourse on art, the technique itself is not neutral, despite its legends." Régis Debray points here the conception of the technique probably the simplest and also the most widespread in the opinion, the media ...: that of the "neutrality" of technology, a concept which Heidegger called "instrumental". Scardigli itself illustrates quite well this instrumental representation, thus concluding his criticism against the new technology: "We must stop waiting for technology that gives meaning to life (...). The technique to remain in its proper place: that of a tool for thought and action, but only a tool, embedded in the culture. "Stiegler states:" There is no thought beyond its supports, even hidden and "internalized".

Organizational Change survey confirmed in this sense the idea that technology influences but does not "cause" a particular structure. "Separate the influence of technology on the organizational structure of other factors and assign a causal role in this factor are very difficult tasks. » (Cyert et Mowery 1987 p. 123)

Whereas until a date the company adapts its technology organization now we find that the company adapts its structure to ICT. We can see how the identification of 'best practices', which serves in particular to model software ERP (Bazet, Mayère, 2004), through formalization contextualised in relation to their specific locations of appearance "The company must adapt to the tool and not the tool to the company. » On the other side, Lemaire and Valenduc indicate that the ERP cannot alone determine the transformation of work: everything depends on the existing structures and strategies for change. "We must break once with the idea of the impact of technology on the organization" (Vinck et al).

The dominant discourse on the ability of ICT to transform organizations is based on well-known examples (the Oticon case described by Bjorn-Andersen and Turner, 1994 ...). However, other examples demonstrate the persistence of traditional forms of organization and the low amplitude of changes related to the introduction of certain T.I (Vandenbosch, Ginzberg 1996). 


\section{Technology as a state of mind: an ideology}

Our starting point is: no technology is "neutral" (Ellul, 1954), when introduced into an organization, some type of organizational design comes "naturally" the technology in question. A message in this sense is designed by Martin Heidegger to the naive who think that technology is a neutral tool: "... When, however, we consider technology as something neutral, that is when we delivered it to the worst way, because this design, which joins a special favor, makes us completely blind in front of the genesis of that .... . ".

These clarifications concern us, we are slaves to technology. Should this mean that we have nothing better to do than passively adapt to technology, while claiming that it is merely a soulless tool?

A technical object is not only subject to an internal technical rational, but it is also subject to the inspiration of a whole series of intermediate social groups .So before an opaque tool, a "black box" after a "process closure" that makes you forget its social genesis, a technical tool is the result of a journey of social interests throughout the process of design. It is therefore not exclusively the criterion of technical (or economic) efficiency which determines the choice between different possible alternatives.

In this sense, "substantialist" theories give technical mediation substantial content that goes beyond mere instrumentality. They argue that the technique is not neutral, but embodies specific values. Dissemination and progress is not innocent. Substantialism shares deterministic mistrust regarding human activity, but denies technical neutrality. For example, Ellul (1988, p. 571) believes that the ends are so completely included in the technical means to carry out that it makes no sense to distinguish between means and ends.

Critical theories, such as the left eddy antiutopianism, give more importance to human action and reject the idea of technological neutrality. Essentialist thinkers consider an "essence" of the erroneous technique, reduced to the concern for efficiency, blinding them on their own limits and without yet being able to demonstrate this "essential" character. As Habermas analyzes "Science and technology as ideology": the technique is a proof of strength and experience. Similarly, Heidegger's "Essays and conferences, the question of the art" technology not only represents a set of means to achieve certain ends, but way to be compared to the truth and to be a vision of the world: "the essence of the technique is not instrumental: the technique, the knowledge itself. "

Constructivism in this respect considers the objects, as well as institutions, to be neither neutral nor independent. So there are underlying political implications. Feenberg cites as an example the deskilling of work, alienation from mass culture and bureaucratisation of society as a consequence not of progress as such, but of individual choice techniques that could well have been different. What to remember about this constructivist approach is that it allows considering art as a social construction.

By theorists in communication sciences we quote the sociologist Herbert Marshall McLuhan (1967), in his book "Understanding Media", known by his famous phrase "the medium is the message"; he stipulates that even independently of the content, it is the way one reaches it that becomes determinant hence the non-neutrality of the technology. It influences its users, reshaping their world view and condition (Brian Martin 1996).

We use the social sciences as their key objective is to develop a better understanding of technological and organizational change. The use of technology, such as ICT, is actually not neutral and will encourage some vision and some organizational design. This issue is part of an inevitable change of context where technology is not a simple instrument but rather a practical one (and Karsten Jones, 2008). The object of such a position is that technology represents an 
external force that exerts an influence on humans and on the organization The technology transforms the properties of the organization (structure, performance, size, etc.), as well as the individual dimensions of the users (satisfaction, complexity of task, level of qualification, communication, productivity, etc.) (WJ Orlikowski 1992; KH Roberts and Mr. Grabowski 1995).

The structurationist approach is original at this level to the extent that it uncovers the equivocal nature of ICT, through the concept of "social structures in the Technology" (Orlikowski, 1992; De- Sanctis and Poole, 1994). As Weick points out, ICT is deeply ambiguous as it can be designed and used in many ways. Barley uncovers the idea of "social meaning" of technology. A major role in structuring actions of individuals is played by ICT in the organization, thanks to its storage capacity, recording and transmission of information (Zuboff, 1988). Many empirical studies (Ngwenyama 1998) used the approach in structurationist longitudinal analysis of the introduction of Lotus Notes.

In another setting, the socio-technical approach affirms the non neutrality of technology for the reciprocal relationships that develop between man-machine bringing the social dynamics related to the use of information technologies in three extreme situations in an «archetypal "model. These are "socio-technical configurations described through structuring dimensions", neutral, disruptive and regenerated (Vaujany, 2001).

However, despite the contribution of these theories in the clarification of our original question, we recognize they refer to a very simplistic image of technology, yet giving primacy of the individual over the technology. On the other side, Foucault's approach fills these limitations by favoring "behavioral and social technologies encoded in hardware technologies" (Willcocks, 2004, p.289).

The different theories on the ICT report / organizational change can tell us about the likely impact of an exemplary standardization and the issue of predictable changes emerging. Reix (1999) indicates uncertainty expected effects of technology, what may be called the moderate effects of the organizational context. According to this approach, the use and the NICT effects emerge in an unpredictable way from human machine interactions. Policymakers choose ICT and announce targets on its adoption, however, the setting application of the latter is carried out in an already established organization and its use is not so invariable. This said that NICTs have a potential impact on the organization an approach that contradicts the deterministic vision. Reix (1999) MARCINIAK and Rowe (1997) and De Roo (1998)) believe that this approach is the most realistic, but must be confirmed empirically. The empirical verification attempts were many, especially among supporters of the theories of organizational contingency (Blau et $\mathrm{Al}$, For example). In this sense, Woodward( 1965) specifies: «At the extremes of the technical scale the physical workflow restricted organizational choice, with the result that firms in the continuous-flow and jobbing production categories tended to be homogeneous as far as organization was concerned. Between these two extremes, however, in the batch production area, the physical work flow did not so much determine organization as define the limits within which it could be determined». In other words, even for supporters of technological determinism, there are "degrees of freedom, power," technology does not determine relentlessly the shape of the organization.

\section{Conclusion}

The organization is not autonomous enough so that we can analyze most of its functions in relation to its internal structure and not to its external environment, but rather an open system.

Information technology and systems are part of a process to redefine both technology and organization; social relationships are mediated by the organization and technology (Doolin, 2004; Bloomfield and Coombs, 1992). 
Technology has become an open system whose elements are constantly in a state of receptivity with the environment, influencing it and undergoing its influence. At the same time, it is a reflection of the environment; it determines relations with the surrounding elements (Viegas, 1984).

It is in this sense that one says that technology is not neutral. It reflects, but at the same time conditions, the relations of production, relations of work and power, tastes and aspirations of individuals and the organization as a whole.

\section{References}

FEENBERG, A. (2004), «(RE) Penser La Technique - Vers une Technologie Démocratique », PARIS, la découverte, Mauss, p. 8.

SERRES, A. (1995) « L'Obsession de la « Question technique »: Pour un autre regard sur les technologies numériques ». domain_shs.info.educ.

ASKENAZY, P. GIANELLA.C, (2000) « Le Paradoxe De Productivité : Les Changements Organisationnels, Facteur Complémentaire a L'informatisation » Economie Et Statistique, $n^{\circ} 339-340$

STIEGLER, B. (1988) «L'Effondrement Technologique Du Temps Traverses», $\mathrm{n}^{\circ}$ 44-45, p. 5

BESSON, P. (1999) «Les ERP à l'épreuve De L'organisation». Systems D'information Et Management. Vol.4, N, p 21-51.

ALSENE, E. (1990), «Les Impacts De La Technologie Sur L'organisation, Sociologie Du Travail », Vol. 32, No. 3 p. 321-337. Published by: Association Pour Le Développement De La Sociologie $\mathrm{Du}$ Travail.

DE VAUJANY, F. (2003) «Figures That Manage Sociotechnical Change» Author Manuscript, Published In «Sociologie Du Travail » Vol 45, N²4, p 515-536

GREENAN, N. (1996). «Innovation Technologique, Changements Organisationnels Et Evolution Des
Compétences » Economie et Statistique, n²98 p. 15-33.

Letourneux, J. (2006), «Humaniser les TIC », Hermès, La Revue, 2/2006 (n ${ }^{\circ}$ 45), p. 147-152.

REVEL, J. (2009) «MICHEL FOUCAULT: Repenser La Technique», Revue De Sciences Humaines, p .16

HABERMAS, J. (1973), « La Technique Et La Science Comme Idéologie », PARIS, DENOEL \& GONTHIER,

ROBERT, P. (2009) «Une Théorie Sociétale Des TIC. Penser Les TIC Entre Approche Critique Et Modélisation Conceptuelle» HERMES LAVOISIER, Coll. Communication, Médiation Et Construits Sociaux.

Musso, P. (2009). « Usages et imaginaires des TIC. L'evolution des cultures numériques », FYP éditions, p.201-210

Benghozi, P. (2001). « Technologies de l'information et organisation : de la tentation ‘à la flexibilité ‘à la centralisation ». Gestion 2000, Recherches et Publications en Management A.S.B.L., p.61-80.

STIEGLER, B. (1994). « La faute d’Epiméthée ». Paris Galilée; La Cite Des Sciences Et De L'industrie.

MARTIN, B. (1996) «Technological Vulnerability", Published in Technology In Society», Vol. 12, No. 4, p. 511-523.

DURAND, T. (1999), «Le Management De La Technologie Et De L'innovation», L'Encyclopédie De La Gestion Et Du Management, R LE DUFF.

PESUEUX, Y. (2009) «Technologie, Technique Et Outils De Gestion ». Journée D'étude MT0, Montpellier, France. p.1-12. 


\section{Notes}

The Importance of Technology :This is a matter of technology rather than technical, we see that there is a substitution between the two terms. To simplify we retain that technology is the critical study, the description of techniques or processes so we used interchangeably a word or the other.
Organizational Change survey: This unique survey provides both detailed information on technological innovations and organizational changes that have affected the production of enterprises. It was conducted in 1993 by the Sessi (Statistical Service of the Ministry of Industry), in partnership with INSEE, and focuses on a representative sample of 1824 companies with more than 50 employees from manufacturing (Fréchou and Greenan1995). 